\title{
Patients, Public and Service Users are Experts by Experience: An Overview from Ophthalmology Research in Canada, UK and Beyond
}

\author{
Andrew M. Skilton (D) - Leslie G. Low $\cdot$ Helen Dimaras
}

Received: December 17, 2019 / Published online: February 29, 2020

(C) The Author(s) 2020

\section{ABSTRACT}

Discussion of the positive impact on research and mutual benefit that arises through genuine researcher and expert by experience collaboration has been noticeably absent from global sight loss and vision conferences. This article is co-authored by a parent advocate whose children have bilateral retinoblastoma, an eye health researcher and a practitioner in patient and public involvement in research who came together at the 2019 annual meeting of the Association for Research in Vision and

Enhanced Digital Features To view enhanced digital features for this article go to https://doi.org/10.6084/ m9.figshare.11627463.

\section{A. M. Skilton $(\square)$}

NIHR Biomedical Research Center, Moorfields Eye Hospital NHS Foundation Trust and UCL Institute of Ophthalmology, London, UK

e-mail: andi.skilton@nihr.ac.uk

A. M. Skilton

NIHR Clinical Research Network Coordinating

Center, London, UK

L. G. Low · H. Dimaras

The Canadian Retinoblastoma Research Advisory

Board, Toronto ON, Canada
Ophthalmology to share their first-hand experiences. The aim of this commentary is to highlight good practice and encourage colleagues to pursue steps towards a more engaged ophthalmology research landscape globally.

\section{PLAIN LANGUAGE SUMMARY}

Through living with conditions and/or engaging with health and social care services patients, public and service users become experts by experience. In Canada and the UK, the active involvement of experts by experience in ophthalmology research (as well as in

\footnotetext{
H. Dimaras

Department of Ophthalmology and Vision Sciences, The Hospital for Sick Children, Toronto ON, Canada

H. Dimaras

Department of Ophthalmology and Vision Sciences, The University of Toronto, Toronto ON, Canada
} 
other specialties) positively benefits all stages of the research cycle; improves the experience and outcomes for patients taking part in research; drives better engagement between researchers, the public and other key stakeholders; and benefits these expert's own sense of wellbeing and achievement. At the moment, the extent to which experts by experience are active in ophthalmology research around the world is unclear, but likely to be minimal. To enable more research to benefit from the contribution of experts by experience, global efforts to improve the continuity and quality of reporting and evidence of impact are needed.

Keywords: Bilateral retinoblastoma; Canada; Engagement; Expert by experience; Involvement; Lived experience; Patient; Patientoriented; PPI; UK

\section{Key Summary Points}

Patients, public and service users are experts by experience through living with conditions and/or engaging with health and social care services.

The active involvement of experts by experience in research decision-making can positively influence their sense of wellbeing and achievement as well as positively benefit the research.

In Canadian and UK ophthalmology, experts by experience are working with researchers to drive better public engagement and to influence patientcentric research priorities and outcomes.

Global efforts are required to raise the quality of reporting and evidencing of the value and impact that partnering with experts by experience has for research.

\section{PATIENT EXPERIENCE}

"You are having triplets, and they are all boys!" I thought these would be the most life-altering words I would ever encounter. However, when my triplets were only 3 months old, I was again given shocking news by a health professional. "All of your triplets have bilateral retinoblastoma." Our triplets are identical and carry a mutation which caused them to develop tumors in their eyes and puts them at high risk for developing other cancers throughout their lives. Testing shows that the mutation began with them and was not inherited. They have a $50 \%$ chance of passing the mutation to their children.

A few days after diagnosis, we boarded an airplane and flew to Sick Kids Hospital in Toronto, Ontario, Canada, to receive specialized treatment. We would travel numerous times over the next 18 months as they needed to be examined under anesthetic about every 3 weeks. Some of the tests and procedures they received were laser, cryotherapy, chemo injections, intravitreal chemo injections, vitrectomy, magnetic resonance imaging, computerized tomography scans, ultrasounds, bone marrow aspiration, lumbar puncture, portacath and systemic chemo. Within the first year, each of the triplets had an enucleation in order to avoid more invasive treatments and to prevent cancer from spreading. As a result of their treatment, each of their remaining eyes has 20/20 vision and they remain stable - we are very fortunate.

I became very informed about the disease and genuinely curious about advancements in research. I wanted to help provide a better outcome and future for children affected by retinoblastoma. In 2016, I was invited to speak at "One Rb World" in Dublin [1], Ireland. I had the opportunity to interact with a worldwide group of retinoblastoma professionals and patients. I met Dr Helen Dimaras who leads the retinoblastoma research team at Sick Kids and learned about their new program called the Canadian Retinoblastoma Research Advisory Board (CRRAB) [2]. I participated in the first CRRAB meeting in 2016 through video conferencing. I also attended the 2019 meeting and 
found it very beneficial to connect in-person to professionals and patients. These meetings have motivated me to participate more fully in CRRAB. Through the collaboration of patients and professionals, CRRAB has created the top ten retinoblastoma research priorities and is now working on driving research forward relating to these.

I am currently a member of two CRRAB working groups. I participate in these working groups through monthly video conference calls. One working group is focused on improving patient engagement. I have registered as a Retinoblastoma Champion, which means I am willing to share my story and to act as an ambassador for the program. In October 2019, I co-organized a Retinoblastoma Family Day in Calgary, Alberta, Canada. We provided an opportunity for 81 professionals and families to gather together and learn about their pathway of care and advancements in research. We also hosted a child life program that addressed and improved anxiety among many of the children.

The second working group is a research development group focusing on the following question from our Top Ten priorities: "How to provide culturally competent social, emotional and psychological support to retinoblastoma patients, survivors, parents and families (at diagnosis and beyond)?" We are currently in the process of applying for grants to implement a protocol assessing and addressing the psychosocial needs of patients and their families. While I do not have a background in research and much of the technical details are difficult to understand, I believe my participation has provided a valuable role. I have been able to give a patient's perspective about data collection and provided out-of-the-box suggestions.

Through my participation, I have learned more about the disease and how to better advocate for my children's care. I have developed valuable relationships with professionals in the field who value my input. I have come to understand how research takes time, but that it is important to learn and to study before implementing. I am so thankful for the opportunity to participate and hope I can help improve care for children impacted by retinoblastoma worldwide."

\section{THE POWER OF THE PATIENT EXPERIENCE}

Leslie's personal experience and how this has motivated a desire to get involved in health research reflects a global movement whereby meaningful and committed partnerships between researchers and experts by experience are closing the gap between what researchers think patients want and need, and what they actually do want and need. When these partnerships are at their best, patients may report a better understanding of the research process, emotional and psychological benefits as well as skill development and a greater awareness and capacity with which to manage their own health journey. For researchers, a better understanding of the patient experience positively impacts the design, delivery and dissemination of research, including the funding, ethics, recruitment and retention stages [3].

\section{CANADIAN EXPERIENCE}

In Canada, the Canadian Institutes for Health Research (CIHR) launched the Strategy for Patient-Oriented Research (SPOR) to spur meaningful engagement of patients in research activities [4]. Patients are defined as individuals with lived experience of disease, including informal caregivers. Meaningful research roles for patients are meant to stretch beyond the traditional role of study subjects and include research prioritization, study design, implementation and dissemination.

To fund and sustain patient-oriented research activities, the CIHR partners with Canadian provinces and territories, charities and academic institutions. Still, patient engagement activities in the Canadian research landscape are quite immature, and further effort into documenting the benefits of engagement are required [5].

The Canadian Retinoblastoma Patient Engagement Strategy is one SPOR-supported program aiming to facilitate patient partnership in eye cancer research [6]. It was developed to: (1) identify and include a large diverse group of people affected by retinoblastoma in research; 
(2) share research results with people affected by retinoblastoma; and (3) promote research that is created and led by patients. CRRAB leads this Patient Engagement Strategy. General membership includes people affected by retinoblastoma, clinicians, allied healthcare providers, researchers, engagement experts and policymakers. The CRRAB meets annually to review progress and set the agenda for the year ahead. Annual general meetings are coupled with (1) a family gathering, where clinicians and scientists present the latest research news and findings, and patients share their stories, and (2) a children's program, led by a Child Life specialist with expertise in retinoblastoma. Between annual meetings, working groups meet monthly to advance engagement efforts, connect patients with research opportunities and design research aimed at solving priorities that patients have helped to determine. Determining the Top 10 priorities for Retinoblastoma Research in Canada was an early priority for CRRAB [7]. They were defined following the James Lind Alliance methodology [8] and now serve to guide much of the advocacy and research efforts of CRRAB.

Diabetes Action Canada is another SPORsupported research consortium with heavy involvement of patients in its governance framework to promote and produce patientoriented research [9]. As part of its program, a national diabetic retinopathy screening program aims to improve early detection and save vision among those affected [10].

\section{UK EXPERIENCE}

In the UK, we commonly use the term patient and public involvement (PPI) to describe the recognition of people's lived health experience as a form of expertise that contributes to improving the relevancy and acceptability of health and social care research [11]. In 2006, the UK Government created the National Institute of Health Research (NIHR), now the largest research funder in the UK public sector [12]. NIHR was founded on the existing evidence and policies around PPI from several organizations $[13,14]$ and is now driving a strategy, along with other stakeholders, that is helping to legitimize and formalize PPI in ways that are transforming UK health research [15].

The NIHR research strategy includes ophthalmology, and there is subsequent specific infrastructure in place that includes the NIHR Biomedical Research Center (Moorfields BRC) and Clinical Research Facility at Moorfields Eye Hospital and the UCL Institute of Ophthalmology and the NIHR Clinical Research Network's (CRN) Ophthalmology Specialty. In 2019, the CRN reported nation-wide growth, since 2010, of its Ophthalmology research portfolio [16]. Moorfields BRC has also seen increasing interest and activity in PPI for vision research from patients and researchers during the same period. Given that NIHR requires PPI in all its funded research and that there are PPI strategies in place throughout NIHR's infrastructure, it would not be unreasonable to assume that PPI opportunities in UK ophthalmology may be on the rise.

The James Lind Alliance Sight Loss and Vision Priority Setting Partnership (SLV-PSP) is the most significant initiative to date that involves the UK public in decision-making to shape ophthalmology research [17]. This national survey identified 4461 public questions from 2220 people, of which $65 \%$ had an eye condition. Interim and final prioritization exercises involved hundreds of public contributors in resolving 122 final priorities. While the SLV-PSP has its limitations, to date at least 121 projects directly addressing priorities have received a share of over $£ 10$ million of funding from NIHR, Fight for Sight (FFS), Birdshot Uveitis Society and the Macular Society $[18,19]$. Additionally, FFS and the NIHR Horizon Scanning Center have involved the public in the development of two reports on the potential impacts and barriers of new and emerging technologies globally, 40 to treat inherited retinal diseases (2014) and 130 for corneal disorders (2016), that would also address SLV-PSP priorities [20, 21].

A recent development in PPI for ophthalmology comes via the appointment of seven new Health Data Research Hubs, worth $£ 37$ million, from the UK Government Industrial Strategy Challenge Fund, led by Health Data Research UK. 
These national collaborations, which include the INSIGHT Hub for eye health, involved patients and the public in the award-making panels and will continue to involve patients in decisionmaking on the acceptable use and curation of patient data for research [22]. INSIGHT, which has a strong focus on artificial intelligence, will hopefully build on previous PPI work undertaken in this space by its Google/DeepMind Health partners [23].

\section{INTERNATIONAL PERSPECTIVE}

Despite recognition of patients, the public and service users as experts by experience by a number of global health and research agencies, the equal and equitable inclusion of these experts in research decision-making is principally driven by individuals and at the project level. Awareness of partnerships with experts by experience and indeed the benefits are highly localized and often limited to one's own country and specialty area. When writing this opinion piece and without doing a detailed literature audit, the authors were aware of only one other patient involvement initiative in ophthalmology outside of our own experience: the PRO-Retina Foundation in Germany. This foundation is a patient and research collaboration focused on promoting research into rare genetic retinal disorders, promoting and funding patient-identified research priorities, coordinating a patient registry and providing patient advisory groups for research projects [24].

Finding examples of work involving experts by experience in journals proves difficult due to variable terminology, limited or poor-quality reporting and a range of methodological approaches at play [25]. There is systematic underreporting of this work more generally, and its contribution to the research is often devalued and excluded or sacrificed to fit with publication guidelines. Researchers are inclined to publish in specialist titles, while public experts, who often lack the budgets and academic writing experience to publish in journals, may prefer blogs, websites, social media, reports and toolkits as more publicly accessible channels, but which are more difficult to find.

Broader adoption and awareness of partnering with experts by experience will require changes to research policy, infrastructure, funding and training, as well as proactive awareness-raising among public audiences. Initiatives like the new International PPI Network (@GlobalPPINet on Twitter) may better connect and align pockets of practice towards building capacity and influencing change. There is also a role for journals in encouraging authors to include these activities as standard and to point towards guidance, such as the Patient and Public Engagement Evaluation Tool (PPEET) evaluation tool and Guidance for Reporting Involvement of Patients and Public 2 (GRIPP2) checklist, to raise the quality of evidence and reporting in manuscripts [26, 27].

Partnering with experts by experience to uncover the impact of vision loss on individuals and knowing how best to improve overall outcomes through research have undeniable value. A concerted effort across global ophthalmology research is required to make good practice also common practice.

This article is based on previously conducted studies and does not contain any studies with human participants or animals performed by any of the authors.

\section{ACKNOWLEDGEMENTS}

The views expressed are those of the author(s) and not necessarily those of the NIHR or the Department of Health and Social Care.

Funding. No funding or sponsorship was received for this review or publication of this article.

Authorship. All named authors meet the International Committee of Medical Journal Editors (ICMJE) criteria for authorship for this article, take responsibility for the integrity of the work as a whole, and have given their approval for this version to be published. 
Prior Presentation. The authors would like to thank Dr Lawrence W. Mróz, The British Columbia Support for People and Patient-Oriented Research and Trials (BC SUPPORT) Unit, Canada and Professor Alastair K. Denniston, Consultant Ophthalmologist/Honorary Professor, University Hospitals Birmingham/University of Birmingham, UK who took part in the original special interest group at the 2019 annual meeting of the Association for Research in Vision and Ophthalmology, Inc. (ARVO), where this topic was first discussed.

Disclosures. Andi Skilton, Leslie Low and Helen Dimaras have no disclosures to make.

Compliance with Ethics Guidelines. This article is based on previously conducted studies and does not contain any studies with human participants or animals performed by any of the authors.

Open Access. This article is licensed under a Creative Commons Attribution-NonCommercial 4.0 International License, which permits any non-commercial use, sharing, adaptation, distribution and reproduction in any medium or format, as long as you give appropriate credit to the original author(s) and the source, provide a link to the Creative Commons licence, and indicate if changes were made. The images or other third party material in this article are included in the article's Creative Commons licence, unless indicated otherwise in a credit line to the material. If material is not included in the article's Creative Commons licence and your intended use is not permitted by statutory regulation or exceeds the permitted use, you will need to obtain permission directly from the copyright holder. To view a copy of this licence, visit http://creativecommons.org/licenses/by$\mathrm{nc} / 4.0 /$.

\section{REFERENCES}

1. World Eye Care Hope. One RB World. https:// wechope.org/programs/one-rb-world. Accessed 21 Feb 2020.
2. Canadian Retinoblastoma Research Advisory Board (CRRAB). https://lab.research.sickkids.ca/dimaras/ research/engagement/strategy. Accessed 21 Feb 2020.

3. Brett J, Staniszewska S, Mockford C, Seers K, HerronMarx S, Bayliss H. The PIRICOM study: a systematic review of the conceptualisation, measurement, impact and outcomes of patients and public involvement in health and social care research: UK Clinical Research Collaboration; 2010. http://www.ukcrc.org/wp-con tent/uploads/2014/03/Piricom+Review+Final+2010. pdf. Accessed 21 Feb 2020.

4. Canadian Institutes of Health Research. Canada's strategy for patient-oriented research. http://www. cihr-irsc.gc.ca/e/44000.html. Accessed 21 Feb 2020.

5. Manafo E, Petermann L, Mason-Lai P, VandallWalker V. Patient engagement in Canada: a scoping review of the 'how' and 'what' of patient engagement in health research. BMC Health Res Policy Syst. 2018;16(1):5.

6. White E, Baddeliyanage R, Shaikh F, Dimaras H. Meaningful patient engagement in research: lessons from retinoblastoma. Pediatrics. 2019;143(6): e20182166.

7. RB Canada Research. http://www.rbcanadaresearch. com. Accessed 21 Feb 2020.

8. James Lind Alliance. The James Lind Alliance Guidebook. http://www.jla.nihr.ac.uk/jla-guidebook. Accessed 21 Feb 2020.

9. Willison DJ, Trowbridge J, Greiver M, Keshavjee K, Mumford D, Sullivan F. Participatory governance over research in an academic research network: the case of Diabetes Action Canada. BMJ Open. 2019;9(4):e026828.

10. Michael Smith Foundation for Health Research. Diabetic Retinopathy Screening-National TeleOphthalmology. https://www.msfhr.org/diabeticretinopathy-screening-national-tele-ophthalmology. Accessed 21 Feb 2020.

11. NIHR INVOLVE Coordinating Centre. Briefing notes for researchers. February 2012. https://www. invo.org.uk/posttypepublication/involve-briefingnotes-for-researchers. Accessed 21 Feb 2020.

12. NIHR. NIHR Annual Report 2017/18. https://www. nihr.ac.uk/documents/about-us/our-contributionto-research/research-performance/NIHR-AnnualReport-2017-18.pdf. Accessed 21 Feb 2020.

13. Wilson P, Mathie E, Keenan J, et al. ReseArch with Patient and Public invOlvement: a realisT evaluation-the RAPPORT study. Southampton: NIHR Journals Library; September 2015. 
14. Russell J, Greenhalgh T, Taylor M. Patient and public involvement in NIHR research 2006-2019: policy intentions, progress and themes. Oxford: NIHR Oxford Biomedical Research Centre; February 2019. https://oxfordbrc.nihr.ac.uk/wp-content/upl oads/2019/05/NIHR-and-PPI-report-Feb_2019.pdf. Accessed 21 Feb 2020.

15. National Institute for Health Research (NIHR). Going the extra mile report: improving the nation's health and wellbeing through public involvement in research. 2015. https://www.nihr.ac.uk/docum ents/about-us/our-contribution-to-research/how-weinvolve-patients-carers-and-the-public/Going-theExtra-Mile.pdf. Accessed 21 Feb 2020.

16. Dawson SR, Linton E, Beicher $\mathrm{K}$, et al. Ophthalmology research in the UK's National Health Service: the structure and performance of the NIHR's Ophthalmology research portfolio. Eye. 2019;33(4): 610-8.

17. Rowe F, Wormald R, Cable R, et al. The Sight Loss and Vision Priority Setting Partnership (SLV-PSP): overview and results of the research prioritisation survey process. BMJ Open. 2014;4(7):e004905.

18. James Lind Alliance. Funded research. http://www. jla.nihr.ac.uk/making-a-difference/funded-research. htm. Accessed 21 Feb 2020.

19. Fight for Sight. The Sight Loss and Vision Priority Setting Partnership: Funded research. https://www. fightforsight.org.uk/our-research/sight-loss-prioritysetting-partnership/funded-research. Accessed 21 Feb 2020.

20. Smith J, Ward D, Michaelides M, Moore AT, Simpson S. New and emerging technologies for the treatment of inherited retinal diseases: a horizon scanning review. Eye. 2015;29(9):1131-40.

21. Genus T, Simpson S, Ward DJ. New and emerging technologies for corneal disorders. Birmingham: Horizon Scanning Research \& Intelligence Centre; September 2016. https://doi.org/10.13140/RG.2.2. 28367.48800 .

22. Health Data Research UK. The hubs. https://www. hdruk.ac.uk/infrastructure/the-hubs. Accessed 21 Feb 2020 .

23. Suleyman M, Snow R. Recommendations on patient and public involvement and engagement (PPIE) at DeepMind Health. 2017. https://deep mind.com/blog/article/collaborating-with-patients. Accessed 21 Feb 2020.

24. von Gizycki R, Gussek H, Brunsmann F. Pro retina and its foundation: chronology of achievements in research promotion by a rare disease patient community. SM Opthalmol J. 2018;4(1):1014.

25. Rogers M, Bethel A, Boddy K. Development and testing of a Medline search filter for identifying patient and public involvement in health research. Health Info Libr J. 2017;34(2):125-33.

26. McMaster University. Public and Patient Engagement Evaluation Tool (PPEET). https://healthsci. mcmaster.ca/ppe/our-products/public-patient-engag ement-evaluation-tool. Accessed 21 Feb 2020.

27. Staniszewska S, Brett J, Simera I, et al. GRIPP2 reporting checklists: tools to improve reporting of patient and public involvement in research. Res Involv Engage. 2017;3:13. 